\title{
Capacidad movilizadora de la información sobre medio ambiente: la importancia de la calidad pe- riodística para promover una actitud proambiental
}

\author{
Inés RODRÍGUEZ CRUZ \\ Universidad de Sevilla \\ ines.rodriguez.cruz@gmail.com \\ Ma Josefa BezunArtea VAlencia \\ Universidad del País Vasco \\ ofa@bezunartea.net
}

Recibido: 20 de enero de 2015

Aceptado: 9 de junio de 2015

\begin{abstract}
Resumen
Los ciudadanos afirman sentirse muy interesados por el medio ambiente, y parecen haber tomado conciencia del papel que juegan en su deterioro; pero existe una brecha entre este proclamado interés y su actuación ante los problemas ambientales. En noticias publicadas entre 2010 y 2011 sobre la política energética española y Doñana se ha observado cómo pugnan los aspectos económicos, sociales y empresariales con los ambientales. Es digno de estudio, por ello, analizar cómo refleja la prensa ese interés ciudadano; y cómo una cuestión determinante como la calidad de la información puede influir en la actitud ciudadana en cuestiones relacionadas con el entorno. Si la práctica periodística no cumple con calidad su función, condicionará la manifestación social.
\end{abstract}

Palabras clave: medio ambiente, periodismo, calidad, movilización, ciudadanía.

\section{Mobilizing capacity of environmental information: the importance of quality journalism to achieve pro-environmental attitudes}

\begin{abstract}
Citizens say they are very concerned about the environment, and they know the role they play in their deterioration; but there is a gap between this proclaimed interest and the mobilization against environmental problems. Several news published between 2010 and 2011 about the Spanish energy policy and Doñana have economic and social aspects, that sometimes are confused with environmental aspects. It is worthy of study, therefore, to analyze how the press reflects that citizen interest; and how a critical issue as the quality of the information can influence the attitude of citizens in issues related to the environment. If the journalistic practice does not meet quality its function, it will condition the social participation.

Keywords: environment, journalism, quality, mobilization, citizenship.
\end{abstract}

\section{Referencia normalizada}

RODRÍGUEZ CRUZ, Inés y BEZUNARTEA VALENCIA, Ma Josefa (2016): “Capacidad movilizadora de la información sobre medio ambiente: la importancia de la calidad periodística para promover una actitud proambiental". Estudios sobre el Mensaje Periodístico. Vol. 22, Núm. 1 (enero-junio), págs.: 517530. Madrid, Ediciones Complutense.

Sumario: 1. Introducción y estado de la cuestión. 2. Material y métodos. 3. Análisis y resultados; 3.1. Carácter de la respuesta social; 3.2. ¿Cómo reaccionan los actores sociales ante un acontecimiento?; 3.3 . Respuesta mediática al interés social. 4. Discusión y conclusiones. 5. Referencias bibliográficas.

\section{Introducción y estado de la cuestión}

En la actualidad, la unanimidad científica en torno a la gravedad del estado del medio ambiente es prácticamente indiscutible; mientras que el avance del ecologismo se deja 
ver a través de la acción reivindicativa y los partidos verdes. Asimismo, la globalización ha dado a algunos de los problemas ambientales, como el cambio climático, una mayor visibilidad social. En definitiva, el medio ambiente ha pasado a convertirse en un eje de la política contemporánea; y en un elemento integrador y vertebrador que cada vez cala más en la ciudadanía, ante lo cual, los medios de comunicación deben responder con eficacia.

El trabajo de investigación que aquí se presenta parte de tres supuestos:

- El interés y preocupación de la ciudadanía por el medio ambiente que recogen distintos estudios sociológicos y encuestas (Centro de Investigaciones Sociológicas, Ecobarómetro de Andalucía, Eurobarómetro, Encuesta de Percepción Social, etc.).

- La conveniencia de un periodismo que responda en calidad y cantidad a la importancia que el propio hecho ambiental exige.

- La posibilidad de que una información de calidad influya en la capacidad movilizadora de los medios de comunicación.

Para desarrollar y relacionar estas premisas se presta especial atención a las directrices de la Teoría de la agenda setting, que se centra en ese temario configurado por los medios que, necesariamente, tendrá un impacto en la audiencia.

McCombs y Shaw (1993) hablan de dos niveles dentro de la agenda setting. El primero se refiere a una transmisión de temas desde la agenda de los medios hacia la agenda pública. Es decir, los medios no determinan cómo opinar sobre un asunto, sino sobre qué cosas pensar o hablar. El segundo nivel describe los atributos que se le otorgan a estos temas (cómo influye no solo la prevalencia de determinados temas, sino también su enfoque o marco-framing-).

La duda está en conocer por qué se informa de ciertos hechos y de una determinada manera mientras que otros no son reseñados o se narran de forma distinta. En este caso, no hay que olvidar críticas como las de McQuail y su visión de la comunicación de masas como un negocio, donde «la apariencia, el artificio y la sorpresa pueden ser más importantes que la realidad, la verdad y lo evidente» (1991: 225); o las de Bezunartea, quien recuerda que el proceso de producción de las noticias puede verse alterado por la intervención de personas o entidades que, según sus intereses, tratarán de incidir introduciendo unos mensajes o truncando otros (1988: 37).

El resultado es la constitución de una agenda con excesivos valores ajenos a los intereses reales de las audiencias; la práctica de un periodismo alejado de la búsqueda de la veracidad, caracterizado por un uso inadecuado de fuentes informativas, no solo en la necesaria verificación, sino en la falta de diversificación y profundización acordes con la complejidad de las noticias; y, por último, la consecuente pérdida de credibilidad por parte del público.

Una de las soluciones apuntadas por McQuail (1991: 170) es la apuesta por una autoproducción de noticias por parte de los medios: «La libertad creadora debiera reconocerse en la novedad, la experimentación, la autenticidad, el individualismo, en oposición a lo rutinario, lo predecible, lo estandarizado, lo reciclado y lo estereotipado».

El debate acerca de las funciones y responsabilidades atribuibles a los medios, que van más allá de su capacidad para mostrar la realidad social, continúa, por ejemplo, 
en torno a su capacidad para promover ciertos valores y pautas de comportamiento claves. Ello tiene relación con la formulación clásica de Lazarsfeld y Merton acerca de la triple función social atribuible a las comunicaciones de masas: concesión de estatus, imposición de normas sociales y acción narcotizadora sobre los públicos. Esta faceta es de interés debido a las reacciones que puede provocar la información publicada en las audiencias.

Denis McQuail aclara, acerca de este «papel movilizador» que, ya sean modeladores (causa) o reflejos (consecuencia) del cambio, los medios son ante todo «mensajeros relacionados con el cambio», en cuanto que constituyen un elemento más de la sociedad (1991:142). Y añade: «tiene poco sentido hablar de "los medios de comunicación" como si fueran una cosa, y no un conjunto enormemente diverso de mensajes, imágenes e ideas, en gran parte no originados en los mismos medios de comunicación, sino procedentes de la sociedad y "devueltos" a la sociedad» (1991:320).

En el caso que nos ocupa, los ciudadanos afirman sentirse muy interesados por los temas relacionados con el medio ambiente, y parecen haber tomado conciencia de su importancia y problemática, así como del papel que juegan en su deterioro. Sin embargo, existe una brecha entre este interés y su actuación ante los problemas ambientales que se presentan (Díez Nicolás, 2001: 16).

Ante esta disonancia entre actitud y comportamiento, los individuos se excusan a través de los costes de las acciones proambientales, de la desconfianza en la acción del gobierno o en la de los otros ciudadanos, o de la creencia en que la solución solo puede ser tecnológica (aunque tampoco hay que olvidar que en la actualidad se considera «políticamente correcto» mostrar que se tiene una gran preocupación por el medio ambiente).

Con este trabajo se pretende establecer una relación entre interés público y movilización social a través de la información ambiental, donde el nivel de calidad de esta puede ser determinante en el momento en que la ciudadanía decida actuar ante ciertas cuestiones relacionadas con el entorno. En este sentido, una práctica periodística en la que no se mantengan uno estándares mínimos de calidad puede influir en la baja participación social: limitarse a reproducir las distintas posturas u opiniones en conflicto, relegando a un segundo lugar el interés de la ciudadanía; u optar por «un mensaje generalmente descomprometido, discontinuo, descrito muchas veces a través del espectáculo violento de la naturaleza -tsunamis, sequías e inundaciones-, distinto en su expresión a la dirección más nítida del consenso científico y con una incierta influencia en la opinión pública», tal y como describe Díaz Nosty (2009: 99).

Para analizar todas estas cuestiones, se ha escogido el debate generado en los últimos años en torno a la política energética española (PEE), una cuestión de Estado e interés económico general, y el espacio natural de Doñana (END), donde la población local está sumida en una controversia entre conservación y desarrollo bajo la mirada de observadores internacionales.

Ambos temas están copando, cada uno en su ámbito, la atención mediática como importantes retos ambientales. La prensa puede jugar, en este sentido, un papel destacado facilitando u obstaculizando la resolución de los retos estos que conllevan. 
El debate social en torno a ellos protagonizó importantes momentos en 2010 y 2011, pero, como sucede con muchas informaciones sobre temas en los que confluyen aspectos económicos, sociales, empresariales además del impacto ambiental, este último ni siquiera era mencionado o resultaba totalmente intrascendente.

Esto no quiere decir que el periodista tenga que asumir una actitud pro ambiental, sino que debe prestar atención también a lo que subyace, al origen del hecho noticioso, donde en muchas ocasiones se encuentra el componente ambiental.

Consideramos que los casos en los que se confunden las cuestiones económicas, ambientales y políticas reúnen un especial interés en tanto que pueden ser analizados para comprobar si el periodismo ambiental transmite a los receptores, sensibles o no a la correcta conservación de la naturaleza, los aspectos de impacto medioambiental que subyacen en ellas para que estén en condiciones de reaccionar en proporción a las verdaderas dimensiones de los posibles atentados; o si, en cambio son las versiones interesadas de políticos y empresarios las que prevalecen, impidiendo cualquier movimiento social o ecologista.

\section{Material y métodos}

Para el análisis se establecieron unos parámetros a partir de estudios precedentes y bibliografía existente sobre la función de los medios, el periodismo ambiental, la calidad informativa y la relación entre sociedad e información periodística (Bezunartea, 1996; De la Torre y Téramo, 2004; Blanco, 2008; Diezhandino, 2008; Pellegrini et al., 2011). Se siguieron también los trabajos que anteceden al que aquí se expone (Rodríguez, 2009, 2012 y 2013).

El método de la semana construida fue el procedimiento técnico empleado para la elección de la muestra de estudio, así como el diseño de una ficha de categorización para textos informativos con los siguientes parámetros de análisis:

- Género periodístico.

- Origen de la información: otro medio de comunicación, una agencia de noticias, una fuente personal o una documental, una revista científica o el propio diario.

- Contexto: antecedentes y consecuencias.

- Extensión: desde un breve a cuatro páginas del diario.

- Aparición del texto en la portada del diario.

- Sección del diario.

- Reacción social: expositiva (redacción aséptica, sin intervención de fuentes), declarativa (expresión de valores y opiniones de las fuentes) y activa (movilización de la población).

- Grupos sociales destacados: grupos movilizadores, administradores o aquellos provenientes del sector empresarial.

Los datos recogidos por las fichas fueron digitalizados, asignando un número de codificación a las categorías más relevantes para esta investigación. A continuación fueron tratados en una tabla de Microsoft Office Excel 2007 para facilitar la detección de errores. Finalmente, los datos fueron procesados con el programa de estadística SPSS 15.0, de donde se obtuvieron tablas de frecuencia, medias, medianas y modas; 
tablas de contingencia, con cruces y comparativas de variables; y gráficos y cuadros explicativos, de todo lo cual se mostrará lo más significativo.

El trabajo de análisis de contenido posterior (cuantitativo y cualitativo) completó el estudio.

En cuanto a la muestra, se tomaron los artículos informativos publicados desde enero de 2010 a diciembre de 2011 en El País (162) y El Mundo (117), como cabeceras nacionales; y ABC (112), Diario de Cádiz (118) y Huelva Información (224), como locales. En total: 733 textos.

Respecto al período de tiempo, este era lo suficientemente amplio para medir con fiabilidad tanto la cobertura habitual prestada al medio ambiente, como el comportamiento de la prensa ante acontecimientos de magnitud como el accidente nuclear de Fukushima.

Por tanto, los objetivos que han guiado esta investigación son:

- Clarificar las posibilidades de estos contenidos de provocar una respuesta social.

- Identificar qué aspectos del medio ambiente están más representados en los medios, comprobar su tratamiento y su conexión con las necesidades informativas del ciudadano.

- El cumplimiento de estos objetivos buscaba comprobar las siguientes hipótesis:

- Los medios de comunicación no otorgan a la información ambiental la relevancia social que muestran las encuestas de opinión.

- Dan prioridad a la información ambiental que se origina desde instancias oficiales.

- Los temas ambientales que provocan más movilizaciones se relacionan con situaciones de peligro para la salud o la economía.

- La capacidad movilizadora de la información ambiental depende de los contenidos noticiosos.

\section{Análisis y resultados}

El corpus lo conforman 733 textos informativos: 176 del END y 557 de la PEE. La diferencia numérica se debe a que este último hace referencia a un tema delimitado geográficamente y con una incidencia no muy marcada en el interés general de la población, frente a las cuestiones relativas a la PEE, que afectan a un rango mayor de la sociedad y en muchas más facetas. De los 733 textos informativos, 419 correspondían a los temas más comunes hallados en este período de dos años:

Para el END: el agua y los acuíferos, el lince ibérico, el transporte dentro de este espacio protegido, los deslindes y el oleoducto de la Refinería Balboa.

Sorprende el poco seguimiento que tuvo el proyecto del oleoducto, cuya construcción hubiera provocado un importante impacto ambiental y social, de cara incluso a la Unesco, hasta donde llegó este debate. De hecho, algunas denuncias referidas a este y otros hechos provocaron la visita de observadores de este organismo internacional para analizar el estado del espacio.

- Para la PEE: las energías renovables, la energía nuclear, la aplicación de políticas energéticas, el precio de los combustibles y la tarifa eléctrica y la deuda que reclaman las grandes empresas. 
Que las energías renovable y nuclear ocupen los primeros puestos, y que los precios de los combustibles y de la electricidad sean los últimos es algo significativo si lo que queremos es analizar la respuesta social y el interés que despiertan estas informaciones, puesto que a priori aquello que afecta inmediatamente al público es lo que repercute a su economía doméstica, y no tanto el impacto a medio o largo plazo que provoca la instalación de una central nuclear.

Haciendo un análisis por diario, vemos que el que más referencias hizo al END fue Huelva Información (51,70\%), con la clara repercusión del elemento de proximidad como criterio de noticiabilidad, al ser Huelva la provincia que más superficie tiene de este espacio. El tema estrella del diario fue la escasez del agua y el peligro en el que se encuentran sus acuíferos $(43,24 \%)$.

En el caso de un diario de tirada nacional, como El País, los asuntos más seguidos fueron el agua y el lince ibérico (36,36\% cada uno). Sin duda se trata de un número escaso de noticias para el largo período de análisis, pero es lógico que solo destaquen aquellos temas, que aun siendo locales, puedan resultar más trascendentales o de interés para el conjunto de la población española, por la inversión económica que llevan asociada o los intereses políticos y agroganaderos enfrentados.

Respecto a la PEE, los dos diarios que más referencia hicieron al tema fueron $\mathrm{El}$ País (137 textos, el 84,57\%) y Huelva Información (133, el 59,38\%). El primero realizó un seguimiento continuado a las noticias relacionadas con la energía nuclear. De entre todas las noticias relacionadas con la PEE, el $24,82 \%$ se referían a ellas. Por su parte, la cabecera onubense apostó más por las renovables (36,84\%). Esto es así porque, una cuestión que ocupó bastantes páginas durante 2010 y 2011 fue la ubicación del almacén temporal central (ATC) para residuos nucleares, donde Huelva no era un municipio interesado - por tanto, hablamos de una cuestión de interés nacional y no local-; mientras que las renovables, al existir proyectos en Huelva y otras provincias andaluzas, sí era asunto de mayor trascendencia para este diario.

En consecuencia, el agua en Doñana (14,20\%) y las energías renovables $(24,24 \%)$ fueron los dos contenidos más tratados entre los textos informativos analizados de uno y otro bloque temático, gracias al Huelva Información (con 16 y 49 noticias, respectivamente), por ser el que más aportó en ambos casos; les seguían, para el END, el lince ibérico, con el 10,23\% (casi la mitad apareció en la cabecera onubense); y para la PEE, las centrales nucleares, con el $13,11 \%$ (casi la mitad fue publicada en $E l$ País), y las políticas energéticas, con el 12,75\% (el 33,80\% correspondía a El Mundo).

Tabla 1. Textos informativos publicados sobre los temas escogidos para END y PEE (\%).

Fuente: elaboración propia

\begin{tabular}{|l|r|r|r|r|r|r|r|r|r|r|}
\hline \multirow{2}{*}{ Periódico } & \multicolumn{4}{|c|}{ Doñana } & \multicolumn{5}{|c|}{ Política energética } \\
\cline { 2 - 12 } & Agua & $\begin{array}{c}\text { Oleo- } \\
\text { ducto }\end{array}$ & Lince & $\begin{array}{c}\text { Des- } \\
\text { linde }\end{array}$ & $\begin{array}{l}\text { Trans- } \\
\text { porte }\end{array}$ & $\begin{array}{c}\text { Tarif. } \\
\text { eléc. }\end{array}$ & $\begin{array}{c}\text { Nu- } \\
\text { clear }\end{array}$ & Combus. & Renov. & Polít. \\
\hline El País & 16,00 & 0,00 & 22,22 & 33,33 & 9,09 & 24,14 & 46,58 & 15,22 & 14,07 & 28,17 \\
\hline ABC & 0,00 & 0,00 & 5,56 & 0,00 & 0,00 & 20,69 & 12,33 & 19,57 & 17,04 & 14,08 \\
\hline El Mundo & 12,00 & 40,00 & 16,67 & 0,00 & 0,00 & 20,69 & 19,18 & 23,91 & 11,85 & 33,80 \\
\hline Huelva In. & 64,00 & 60,00 & 38,89 & 50,00 & 72,73 & 10,34 & 12,33 & 19,57 & 36,30 & 11,27 \\
\hline TOTAL & $\mathbf{1 0 0 , 0}$ & $\mathbf{1 0 0 , 0}$ & $\mathbf{1 0 0 , 0}$ & $\mathbf{1 0 0 , 0}$ & $\mathbf{1 0 0 , 0}$ & $\mathbf{1 0 0 , 0}$ & $\mathbf{1 0 0 , 0}$ & $\mathbf{1 0 0 , 0}$ & $\mathbf{1 0 0 , 0}$ & $\mathbf{1 0 0 , 0}$ \\
\hline
\end{tabular}




\subsection{Carácter de la respuesta social}

Muchos de los conflictos relacionados con el medio ambiente no se deben tanto a sus posibles efectos sobre la salud o el entorno como a las relaciones que la población mantiene, por ejemplo, con los gestores o reguladores de ese riesgo: la Junta de Andalucía ante el plan de regadíos de Doñana o un ayuntamiento local presentado como candidato para acoger el almacén de residuos nucleares. Pero, además, la población puede mantener cierto grado de dependencia, por afinidad o animadversión, hacia el responsable del hecho o hacia el que se ve perjudicado (los agricultores de Doñana, por ejemplo).

Estos sentimientos pueden explicar el mayor o menor grado de movilización. Por eso, aunque un sector de la población perciba un riesgo elevado ante la instalación de un almacén nuclear, si el que lo promueve es el partido mayoritario, la protesta será reprimida.

En cuanto a la PEE, el 76,8\% de los textos destacaron algún grupo o actor social, sobre todo en las informaciones dedicadas a las energías renovables y, más alejado, en las referidas a las centrales nucleares y las políticas energéticas.

En El País la mayoría de las noticias sobre centrales nucleares se refirieron a la construcción y emplazamiento de un nuevo ATC. La línea editorial no marcó, en este sentido, su postura a favor o en contra de las nucleares (lo que conllevaría un matiz más ambiental), sino que centró su interés en las disputas internas de los partidos, ya que no siempre coincidían las posturas del mismo partido en el municipio o en el gobierno autonómico.

Las informaciones también versaron en torno a las negociaciones entre sindicatos y Gobierno central, de las que surgió una disputa al filtrarse que aquellos estaban dispuestos a aceptar la jubilación a los 67 años a cambio de prorrogar el cierre de la central de Garoña, en 2013, y evitar, de ese modo, la eliminación de puestos de trabajo. Asimismo, en ocasiones, se hizo referencia al viraje político del presidente del Gobierno, José Luis Rodríguez Zapatero, en torno a la prórroga de la vida útil de las centrales nucleares; o a la reacción de los partidos políticos en general a raíz del accidente de Fukushima.

En el asunto de las energías renovables, por el que apostó $A B C$, cabe una amplia variedad de hechos, por lo que es complicado establecer un objetivo común que defina la línea editorial del medio. Lo que sí es destacable es la visión empresarial de estas informaciones, en lugar de la ambiental. Así, cuando se titulan las informaciones con: «Iberdrola construirá cuatro parques eólicos en Hungría» (04/08/2010), «Andalucía priorizará parques eólicos por $800 \mathrm{MW}$ » $(08 / 02 / 2011)$ o «EE.UU. busca alianzas con las renovables y las TICs andaluzas» (02/06/2011), se ve clara esta visión económica o industrial.

En otras informaciones, como «España alcanzará el 35\% de energías renovables en el año 2020» (18/06/2011) o «La oposición al parque eólico marino mantiene su protesta» (28/08/2010), los grupos sociales destacados fueron más variados, lo que supone un enriquecimiento en el debate social: el ayuntamiento promotor de un parque eólico, la empresa y la plataforma ciudadana. En estos casos, el enfoque no es ambiental, pero tampoco político o económico, es más científico y social. 
El caso de El Mundo es similar al de los dos diarios anteriores: aunque los temas por los que apuesta cada cabecera varía, los grupos sociales destacados en ellos, no. Las administraciones y las instituciones públicas y privadas protagonizaron los textos informativos sobre PEE, más aún en las noticias referidas a las distintas medidas políticas propuestas por el Gobierno, por las que apostó este diario: «IU: "A pie, en bicicleta y en tren normal"» (04/03/2011); «Las autonomías rechazan pagar el plan de ahorro» (04/03/2011); «El PP se abstiene al aprobarse el pacto energético en el Congreso» $(18 / 11 / 2010)$.

Si los actores son siempre las instituciones públicas y privadas, el debate no llega por igual a toda la sociedad, o al menos esta no comprende otros enfoques sobre la PEE o el END que no sean los puramente político y empresarial.

Tabla 2. Presencia ambiental en los textos informativos. Fuente: elaboración propia

\begin{tabular}{|l|c|}
\hline Presencia ambiental & Porcentaje (\%) \\
\hline Omisión & 62,48 \\
\hline Superficial & 26,19 \\
\hline Moderada & 5,87 \\
\hline Profunda & 5,46 \\
\hline TOTAL & $\mathbf{1 0 0}$ \\
\hline
\end{tabular}

De ahí la importancia de atender las voces de los grupos que tienden a la acción, pues suelen ser más contestatarios, buscan escenarios más cercanos a las bases sociales (un debate universitario, una manifestación) y su presencia en los medios se basa en algo más que una declaración a pie de calle o una rueda de prensa.

Si nos detenemos en las tres cabeceras analizadas hasta ahora para observar qué asuntos no mediados por instituciones públicas o privadas tienen cabida en sus páginas, obtenemos los siguientes:

- El Pais: la energía nuclear, el recurso del agua en Doñana y la constitución de un partido político proambiental.

- $A B C$ : la energía nuclear.

- El Mundo: la energía nuclear, la cacería de linces ibéricos en Doñana y la minería.

Así, parece que domina el tema nuclear como uno de los que más movilización social promovió. En cuanto al apoyo de la línea editorial de cada periódico a esta cuestión, El País lo mismo le dio cabida a la petición del lobby nuclear de tres nuevas centrales que a las manifestaciones contrarias a esta fuente de energía, si bien en este caso se trataba solo de una fotonoticia. Algo parecido sucedió con $A B C$, el cual publicó el deseo de un pueblo de albergar un almacén nuclear $\mathrm{y}$, al mismo tiempo, una manifestación contra esta energía, pero en este último caso, lo hizo en un breve. Del mismo modo, en El Mundo las manifestaciones contra el almacén nuclear se recogieron en un breve.

Los casos de Huelva Información y Diario de Cádiz siguieron la misma línea. En un diario local, por tanto, los grupos y sectores representados en las informaciones son los mismos que en la prensa nacional. Sin embargo, en las noticias sobre el agua y los acuíferos de Doñana del diario onubense fue mayor la cantidad y variedad de los 
sectores sociales movilizados, destacando también actores sociales como agricultores, investigadores, expertos, comunidades de regantes y ecologistas que aportaban sus intereses y perspectivas.

Igualmente, en Diario de Cádiz la referencia a grupos activos o movilizadores fue testimonial: «Más de 11.000 firmas contra el parque eólico marino de Chipiona» (20/01/2010); «Piden que no se permita a los coches acceder a la playa de Doñana» (04/08/2010); «La plataforma contra el parque eólico se manifiesta hoy en Chipiona» (28/08/2010); «Un pueblo de Cuenca es 'agraciado' con el almacén de residuos nucleares» $(31 / 12 / 2011)$.

En resumen, se suelen destacar más a las elites económicos y políticas, que tienen más fácil acceso a los medios, en detrimento de otras voces más cercanas a las bases ciudadanas.

\section{2. ¿Cómo reaccionan los actores sociales ante un acontecimiento?}

Lo dicho hasta ahora se puede entender mejor analizando la manera en que los actores de las informaciones han reaccionado ante un hecho informativo, o el tipo de reacción que el medio ha querido plasmar, ya que no es lo mismo que un periodista redacte de manera expositiva, más aséptica podíamos decir, una información en la que no participe ninguna fuente interesada (por ejemplo, una noticia sobre una resolución judicial por la caza de un lince ibérico, complementada con una referencia a la norma ambiental), o que el periodista elabore una noticia a partir de las declaraciones de una y otra parte, en las que se refleje un juicio de valor; o que informe sobre una acción reivindicativa o de protesta de un grupo social.

Para el END, solo se reflejó en prensa una reacción proactiva de un sector de la población en dos noticias:

- El País (21/02/2010): «Roban la vida a Doñana», sobre los pozos ilegales que «esquilman»el acuífero del parque, y en la que intervenían agricultores, ecologistas y la Administración autonómica. El fiscal de Medio Ambiente de Huelva había decido denunciar estos hechos ante la pasividad de la Administración ambiental.

- El País (05/09/2010): «Costas contra todos por Doñana», sobre todas las alegaciones contra el deslinde del Parque Nacional de Doñana promovido por el Ministerio de Medio Ambiente. Esta acción del Gobierno promovió un importante revuelo entre los propietarios de los terrenos. Las informaciones sobre las alegaciones fueron la única muestra pública de la existencia de perjudicados por la norma.

En el caso de la PEE, los datos son los siguientes:

- En un 46,89\% las informaciones eran una mera exposición: «Diez trucos para ahorrar en las facturas del agua y la luz» (02/03/2010) o «El impacto económico y la seguridad, claves para instalar el ATC en Cuenca» (31/12/2011), publicadas en $A B C$. El primer caso era una enumeración de métodos para reducir los consumos y el segundo, una relación de las características que avalan el emplazamiento del futuro almacén nuclear. 
- En un 28,53\% se apuntaban declaraciones de las partes interesadas: «Otro pueblo manchego pide el ATC» (28/01/2010) o «Cuenca albergará el cementerio nuclear» $(31 / 12 / 2011)$, con valoraciones y opiniones de políticos.

- En un 19,7\% de los textos no se hacía alusión a ninguna fuente personal interesada, sino que se basaban en fuentes como el boletín petrolero de la Unión Europea, estudios estadísticos, etc.

- En un 3,11\% se acentuaba una reacción activa por parte de un sector de la población, por ejemplo, la protesta de la plataforma ciudadana contra el parque eólico.

- En un 1,69\% se hacía referencia a la manifestación de una parte importante de la sociedad, por ejemplo, las respuestas a una encuesta para el Centro de Investigaciones Sociológicas.

Por periódico, quizás se podría pensar que aquellos de edición local serían más sensibles a una reacción activa de la sociedad, por cercanía y accesibilidad a las fuentes interesadas, pero en realidad no fue así ni para estos ni para los diarios nacionales. En muy pocos casos las informaciones hicieron referencia a ciudadanos o ecologistas; y menor aún fue el número de las que se hicieron eco de protestas y manifestaciones.

\subsection{Respuesta mediática al interés social}

La conjugación del interés social y la relevancia mediática determina la capacidad movilizadora de la información ambiental, la cual depende de si esta cubre o no las necesidades e intereses ciudadanos, es decir, si responde a ellos.

Hablando de movilización social e interés por la información ambiental, es curioso que para el END, de las 11 noticias que aporta El País al análisis, ninguna hiciera referencia al proyecto del oleoducto de la refinería Balboa que, previsiblemente, era un tema impactante a nivel nacional, pues estaban implicadas dos comunidades autónomas y la ejecución de este proyecto dependía de una decisión del Gobierno de España, que llegó en 2012. Y también destaca porque, ante todo, se trata de un proyecto de gran incidencia en el END.

Si nos detenemos en la PEE, y el asunto más tratado, las energías renovables, destaca el caso de $A B C$ que, como otros medios, atiende más a los intereses empresariales que a aquello que pudiera ser de beneficio general por ser más respetuoso con la conservación de la naturaleza. Por ejemplo, destacamos los siguientes titulares:

- «El futuro está en los tejados»: doble página sobre la energía solar.

- «Trabajar por el planeta»: sobre empleo verde en el sector residuos y energías renovables.

- «La energía geotérmica se viste de largo»: publicada también en una doble página.

Al primero y al último se les otorgó una cobertura mediática mayor; sin embargo, son asuntos que, aunque interesantes, han perdido relevancia social por ser temas ya muy conocidos y, a la vez, al alcance de muy pocos ciudadanos. En cambio, el se- 
gundo titular puede despertar más interés entre los lectores, sobre todo si se presenta como una salida a la crisis económica.

Por tanto, son informaciones donde suelen estar representados sectores empresariales, fuentes del ámbito privado, de lo que cabe deducir que se trata de una toma de posición editorial de un periódico sujeto a los principios de una ideología capitalista, que muestran más interés hacia el mundo empresarial que hacia el de las bases sociales.

En el caso de Diario de Cádiz, algunos de los titulares más relevantes socialmente fueron los referidos a la instalación de eólicas marinas en Chipiona, por el impacto que supuso para la población esta medida. La relevancia social se midió en este caso, no solo por la movilización directa de un sector de la población (a través de la creación de una plataforma ciudadana que protagonizó diversas acciones de protesta), sino también por el seguimiento que este diario hizo del tema (continuidad en el tiempo).

Otra variable de estudio fue la proximidad física de las noticias, una de cuyas características es el uso de fuentes informativas locales.

Como podemos observar en la Tabla 1, el uso de fuentes locales no es la tendencia mayoritaria, sino el de fuentes informativas nacionales. Solo Huelva Información apuesta, aunque no muy sobradamente, por la proximidad física que conlleva el acceso a actores locales que aportan información a la noticia.

Tabla 3. Área geográfica de las fuentes informativas (\%). Fuente: elaboración propia

\begin{tabular}{|l|r|r|r|r|r|r|r|}
\hline Periódico & $\begin{array}{c}\text { No iden- } \\
\text { tificada }\end{array}$ & Local & Regional & Nacional & Europea & $\begin{array}{l}\text { Fuera } \\
\text { Europa }\end{array}$ & TOTAL \\
\hline El País & 7,18 & 16,67 & 11,79 & 55,90 & 4,36 & 4,10 & 100,00 \\
\hline ABC & 8,10 & 28,57 & 18,10 & 35,71 & 5,24 & 4,29 & 100,00 \\
\hline El Mundo & 12,22 & 12,22 & 12,22 & 52,49 & 4,98 & 5,88 & 100,00 \\
\hline Huelva I. & 6,36 & 35,55 & 21,39 & 31,50 & 3,47 & 1,73 & 100,00 \\
\hline D. Cádiz & 4,37 & 34,97 & 13,66 & 39,34 & 6,01 & 1,64 & 100,00 \\
\hline TOTAL & $\mathbf{7 , 5 6}$ & $\mathbf{2 5 , 1 1}$ & $\mathbf{1 5 , 5 6}$ & $\mathbf{4 3 , 7 0}$ & $\mathbf{4 , 5 9}$ & $\mathbf{3 , 4 8}$ & $\mathbf{1 0 0 , 0 0}$ \\
\hline
\end{tabular}

El impacto que provocan un huerto solar en un municipio, la subida del precio de la gasolina o la instalación de un almacén nuclear pueden llevar aparejada una movilización social mayor dependiendo de las fuentes informativas a las que recurra el periodista: no es lo mismo que se destaquen las declaraciones del presidente de la Junta de Andalucía, por muy mediáticas que sean sus palabras, que se hable de cómo ha afectado la instalación de renovables en otros municipios; o que se publique periódicamente el precio de la gasolina, según el boletín petrolífero europeo, a que se dé voz a un experto sobre la dependencia energética española de países petrolíferos en conflicto.

Además, el enfoque que adquieren las noticias por medio del uso de ciertas fuentes informativas está muy alejado de la cuestión ambiental, acercándose más a la economía y la seguridad ciudadana o a la simple agenda política.

Dicho con un ejemplo, el tema del agua fue el que mayor número de noticias produjo y en el que estuvieron representados más sectores sociales interesados, lo que se reflejó en la diversidad de fuentes informativas utilizadas (agricultores, Administración pública y ecologistas), enfrentadas sobre qué debe prevalecer: limitar el uso de los acuíferos, defendido por los conservacionistas, o conceder mayor flexibilidad en beneficio del desarrollo económico, defendido por los agricultores. A esto hay que unir el entorno en el que se desarrolla, Doñana, que además de ser un territorio pro- 
tegido, lo es gracias a muchas figuras internacionales ante las que hay que responder, aunque esto no trascendió en las noticias analizadas.

\section{Discusión y conclusiones}

Tras el análisis de la repercusión social de la información ambiental, se puede confirmar que ni el tratamiento de los medios ni la respuesta social concuerdan con los datos sociológicos que aseguran que para la ciudadanía el medio ambiente es una preocupación personal importante. Ni en el contenido de los medios, ni en la respuesta social sobre dos temas de tan notable implicación ecológica como Doñana y la política energética española se manifiestan tales preocupaciones.

En las noticias analizadas el enfoque sobre el medio ambiente o no se menciona en absoluto o queda totalmente oscurecido por los aspectos empresarial-económico o político-ideológico o por los intereses inmediatos de los afectados, precisamente, por las medidas proteccionistas.

La segunda hipótesis de partida era que los medios de comunicación dan prioridad a la información ambiental que se origina desde instancias oficiales. Efectivamente, esta información padece de la ofensiva de las fuentes interesadas: son los sectores gubernamentales, institucionales y empresariales quienes marcan los temas, los contenidos y hasta el enfoque, en detrimento de fuentes expertas, que aportarían más datos técnicos e independientes.

Así, los contenidos analizados tenían como portavoces preferentes, cuando no únicos, los de los sectores económico y político. Esta falta de iniciativa de los periodistas es una de las principales rémoras de la profesión.

Como consecuencia de lo apuntado, vemos que la tercera hipótesis planteada se cumple solo en parte, ya que la respuesta social promovida por temas ambientales se produce sobre todo desde un punto de vista conservacionista: cambio climático, contaminación, desaparición de especies, además de otras relacionadas con sucesos como accidentes nucleares.

Los medios muestran en este sentido una actitud limitada sobre el medio ambiente. Son escasas las ocasiones en las que se acercan al tema energético y a Doñana desde una perspectiva ambiental. Y, cuando lo hacen, es desde el lado conservacionista. Por ejemplo, las posiciones más estrictamente ecológicas aparecen en las denuncias por las muertes de linces por atropello, caza furtiva o envenenamiento; $y$, sin embargo, no se muestra esa actitud ecológica frente al agotamiento de los acuíferos de Doñana.

Y ello es porque los medios relegan el lado ambiental de la política energética española y de Doñana a favor del económico y político. Al ignorar la relevancia ambiental de estas cuestiones, marginan asuntos de interés como las consecuencias para el entorno de una política energética basada en recursos naturales perecederos que, además, tienen que importarse; o las repercusiones sobre el medio ambiente del actual mercado energético español, donde los precios de la energía no solo repercuten en la competitividad económica sino también en la sostenibilidad ambiental del sistema.

Sobre la explotación de los acuíferos en Doñana predomina la voz de los agricultores perjudicados por la restricción de agua, mientras apenas se prestó atención a la posible construcción del oleoducto, a pesar de las llamadas de atención de la Unesco. 
Respecto de la política energética, destaca lo relativo a las fuentes renovables, pero siempre desde la perspectiva del desarrollo económico.

Por tanto, los medios no son sensibles a las manifestaciones y exteriorizaciones públicas promovidas por temas ambientales; estas apenas se observan o son de una escasa intensidad reivindicativa, siendo sus protagonistas ecologistas y asociaciones vecinales, sobre todo.

Solo se ha registrado un seguimiento mediático acusado en torno a dos temas: a favor o en contra de la instalación de un cementerio nuclear y en contra de la construcción de un parque eólico marino frente a la costa de Cádiz.

Por todo ello, la información sobre medio ambiente no provoca una respuesta social activa. En relación a los dos temas analizados, apenas se dan 19 noticias (17 sobre la política energética y dos sobre Doñana) en los que se reflejan este tipo de reacciones (y no siempre bajo un prisma ambiental): ecologistas contra regantes, regantes contra la Junta de Andalucía; antinucleares contra la ubicación del cementerio de residuos, vecinos contra un parque eólico marítimo.

El interés por el medio ambiente, por tanto, se manifiesta en el plano teórico. Cuando se debate sobre una cuestión que afecta al entorno, se hace centrándose en aquellas facetas que repercuten en la población en lo que se refiere a su estándar de vida o a sus intereses directos: economía, seguridad, salud, etc.

Se puede decir entonces que la información ambiental en muchos casos no provoca una respuesta social activa porque, sencillamente, no es ambiental; es información económica o política, pero no ambiental.

En definitiva, sería necesaria una redefinición de la información ambiental para que esta fuera un elemento tan revelador que la opinión pública tomara conciencia de la problemática del medio ambiente. Esto supondría anular, por un lado, las etiquetas tradicionales mediáticas asociadas a "lo verde" y, al mismo tiempo, dar otro sentido a las informaciones que, con un trasfondo ambiental importante, solo se analizan desde el punto de vista político y económico.

\section{Referencias bibliográficas}

BEZUNARTEA, Ofa (1998): Noticias e ideología profesional. La prensa vasca en la transición política. Bilbao, Deusto.

BEZUNARTEA, Ofa (1996): «El uso de las declaraciones en la información política». Estudios de Periodística $V$, Pontevedra.

BLANCO LEAL, María del Mar (2008): Modelos de análisis para el estudio crítico de la prensa. Madrid, Ediciones Internacionales Universitarias.

DE LA TORRE, Lidia y TÉRAMO, María Teresa (2004): La noticia en el espejo. Medición de la calidad periodística: la información y su público. Buenos Aires, Educa.

DÍAZ NOSTY, Bernardo (2009): «Cambio climático, consenso científico y construcción mediática. Los paradigmas de la comunicación para la sostenibilidad». Revista Latina de Comunicación Social [en línea]. Tenerife (Canarias): Universidad de la 
Laguna, vol. 12, $\mathrm{n}^{\circ}$ 64. p. 99-119: http://www.redalyc.org/articulo.oa?id $=81911786009$. [fecha de consulta: 4 de enero de 2015].

DÍEZ NICOLÁS, Juan (2001): El dilema de la supervivencia. Los españoles ante el Medio Ambiente. Madrid, Obra Social Caja Madrid.

DIEZHANDINO, María Pilar (coord., 2008): Periodismo en la era de Internet. Claves para entender la situación actual de la información periodística en España. Madrid, Colección Fundación Telefónica; Ariel.

McCOMBS, Maxwell E. and SHAW, Donald L. (1993): "The Evolution of AgendaSetting Research: Twenty-Five Years in the Marketplace of Ideas". Journal of Communication, vol. 43, num. 2. pp. 58-67.

McQUAIL, Denis (1991): Introducción a la teoría de la comunicación de masas. Galmarini, Marco Aurelio (trad.). Barcelona, Ediciones Paidós Ibérica Comunicación.

PELLEGRINI, Silvia et al. (2011): Valor agregado periodístico. La apuesta por la calidad de las noticias. Santiago de Chile, Ediciones Universidad Católica de Chile.

RODRÍGUEZ CRUZ, Inés (2012).: “Análisis cuantitativo y calidad de la información sobre medio ambiente en la prensa española". Comunicación y Riegos: Comunicaciones del III Congreso Internacional Asociación Española de Investigación de la Comunicación (Tarragona, 18-20 de enero de 2012). [S.1.]: Asociación Española de Investigación de la Comunicación. 1 disco compacto.

RODRÍGUEZ CRUZ, Inés (2009): “Análisis cuantitativo y calidad de la información sobre el medio ambiente en la prensa española". Trabajo de investigación (inédito). Universidad de Sevilla, Facultad de Comunicación, Departamento de Periodismo II.

RODRÍGUEZ CRUZ, Inés (2013): "La calidad de la información sobre medio ambiente”, en GÓMEZ MOMPART, Josep Lluís et al.: La calidad periodística. Teorías, investigaciones y sugerencias profesionales. Castelló de la Plana [etc.]: Publicacions de la Unversitat Jaume I [etc.]. pp. 177-190.

Inés Rodríguez Cruz es doctora en Periodismo por la Universidad de Sevilla. Es miembro del Grupo de Investigación Estudio de Medios para un Periodismo de Calidad. Departamento de Periodismo II. Facultad de Ciencias de la Información. Universidad de Sevilla.

$\mathbf{M}^{\mathrm{a}}$ Josefa Bezunartea Valencia es catedrática de Periodismo en la Universidad del País Vasco. Es miembro del Grupo de Investigación Estudio de Medios para un Periodismo de Calidad. Departamento de Periodismo II. Facultad de Ciencias de la Información. Universidad de Sevilla. 